\section{Guide to authors of contributions to Nature}

Nature is a weekly international journal covering all the sciences. It is intended for an interdisciplinary readership, so all manuscripts should be written clearly and simply. Contributors should pay particular attention to the fact that English is not the first language of many readers. Space is limited and competition severe, so brevity is highly valued. The length limits below are specified in terms of the number of pages taken up in Nature. An uninterrupted page of text contains about 1,300 words, so a typical Letter to Nature, occupying $2 \frac{1}{2}$ pages, can contain about 1,500 words of text and four modest display items (figures and/or tables) with brief legends. There are no formal limits on the number of display items, but extra display material must be accompanied by commensurate reductions in the length of the text. Length limits can, however, be varied upwards or downwards at the editors' discretion.

Nature publishes the following types of contribution:

Review Articles survey recent developments in a topical area of scientific research. They should not generally occupy more than 6 pages of Nature.

Progress articles are relatively informal reviews of particularly topical and fast-moving fields. They do not exceed 4 pages of Nature.

Contributors wishing to submit a Review Article or Progress should first send a one-page synopsis to the Reviews Coordinator, from whom guidelines are available on request.

Articles are reports of original scientific research whose conclusions represent a substantial advance in understanding of an important problem and are of broad general interest. They do not generally exceed 5 pages of Nature and have no more than 50 references. They have a 'heading' of up to 80 words, often rewritten by Nature's editors, which advertises the content of the paper in general terms and should not contain numbers, abbreviations or measurements unless central to the message of the paper. The introduction and summary should be contained in the first three or four paragraphs of the main text. Layout of methods, figures and legends is summarized below.

Letters to Nature are short reports of original research focused on an outstanding finding whose implications are of interest to nonspecialists. They should not generally exceed $2 \frac{1}{2}$ pages of Nature. They have a bold first paragraph of not more than 180 words summarizing the background, rationale, conclusions and main implications of the work, aimed particularly at nonspecialist readers. Letters should have no more than 30 references. Layout of methods, figures and legends is summarized below.

\section{Preparation of Articles and Letters}

All manuscripts should be written in English, typed double-spaced on one side of the paper only. Manuscripts submitted in electronic form cannot be considered.

Manuscripts should be accompanied by a brief covering letter from the corresponding author, containing a full postal address, telephone and fax numbers, and e-mail address.

Five copies of manuscripts and original figures are needed, together with two copies of the covering letter. Five copies of manuscripts by any of the authors that have been submitted or are in press elsewhere should also be included, clearly marked as such; failure to do so may prejudice consideration of the manuscript.

Unless otherwise instructed by the editor handling a manuscript, when sending revised or resubmitted manuscripts five copies are required, each accompanied by a copy of the authors' response to referees' and editors' comments on the earlier version.

Titles should not exceed three lines of 31 characters each (including spaces), and should avoid numerical values, acronyms, abbreviations and punctuation wherever possible.

References should be numbered sequentially as they appear in the text, tables and figure legends. Only papers that have been published or submitted to a journal should be in the numbered list: manuscripts in preparation should be mentioned in the text with a list of authors. Reference lists should not contain textual material, grant details or acknowledgements.

Acknowledgements must be brief and appear after the reference list. Nature does not publish grant or contribution numbers.

Figures should not be larger than 22 by $28 \mathrm{~cm}$ unless unavoidable. They should not contain more than one panel unless the assembled parts are logically connected. Each copy should be marked with the corresponding author's name and, when known, the manuscript reference number. One photocopy of the original figures should be provided. All original figures are returned when Nature cannot offer to publish a manuscript, but one copy of the manuscript and a photocopy of the figures are kept in confidential files for three months and then destroyed. Detailed instructions for figure preparation are available from the production department, including details of acceptable digital formats.

Colour figures are welcome but a contribution towards the cost of reproduction is requested. Inability to pay this charge will not prevent Nature publishing figures where colour is essential.

Tables. Symbols and abbreviations in a table should be defined immediately below the table, followed by essential descriptive material, all in double-spaced text. Tables should each be presented on a separate sheet of paper.

Methods. Brief details of materials and methods can be given in the text. Otherwise, they should be described at the end of the text in a section entitled "Methods", subdivided by bold headings referring to the methods used. This section should not exceed 800 words and ideally should be shorter. Additional material can be deposited on Nature's Web site. In contributions with methods sections, figure legends should not exceed 150 words each, and should be confined to a description of the figure and the symbols used.

Materials. As a condition of publication, authors are required to make materials and methods used freely available to academic researchers for their own use. Supporting datasets must be made available at the time of publication from the authors directly, by posting on Nature's Web site, by deposition in the appropriate public database or by distribution on the Internet. In the case of X-ray crystallographic coordinates only, public access may be delayed for up to one year after publication.

Articles and Letters should both contain a statement at the end of

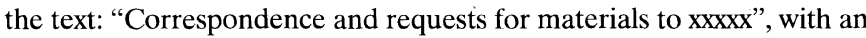
e-mail address if desired, followed by the accession numbers or Web site address for supporting datasets. The designated author need not necessarily be the senior author, but Nature will expect the named author to handle matters arising from published contributions.

Manuscripts can be submitted to the Editor at Nature, Porter's South, Crinan St, London N1 9XW or at Nature, 968 National Press Building, Washington, DC 20045-1938. Proofs should be returned by express mail to London. Fax numbers and e-mail addresses for all editorial offices are on Nature's masthead.

\section{Other contributions}

Nature publishes informal contributed material as follows:

Correspondence contributions are short comments on topical issues, anecdotal material or reactions of readers to nontechnical material published in Nature (mainly News, Briefings, Opinion, Book Review or Commentary articles). All are unsolicited; submissions by e-mail to corres@nature.com are preferred (accents on names and places should be clearly indicated)

Commentary articles are informal, editorial comments on topical issues of public interest that have some bearing on scientific research. They are often controversial. Unsolicited manuscripts are considered, but enquiries can be made to the Commentary Editor by e-mail (nature@nature.com) or fax as a one-page synopsis or informal letter before formal submission.

News and Views articles inform nonspecialist readers about new scientific advances, either as reported in published papers or in the form of meeting reports. Most are commissioned, but proposals can be made to the News and Views Editor in advance of publication of the paper or of the meeting concerned. Authors are not allowed to discuss their own work or work from elsewhere in their institution. Detailed guidelines are available on request.

Scientific Correspondence is a predominantly peer-reviewed section of the journal specializing in very brief reports of general interest and discussion of topical issues. Priority is given to contributions of fewer than 500 words. Detailed guidelines are available on request. All contributions are unsolicited, and should be submitted by mail, not e-mail. Copies of contributions submitted by fax should be sent by mail with original figures and a cover letter noting that the manuscript has been faxed.

Book Reviews are all commissioned by the Book Review Editor. Unsolicited contributions are not considered.

Nature's editors will request final copy for Commentary, News and Views, Scientific Correspondence and Book Reviews on disk or via e-mail, as appropriate.

A more detailed Guide to Authors is available on Nature's WWW sites at http://www.nature.com or http://www.america.nature.com 